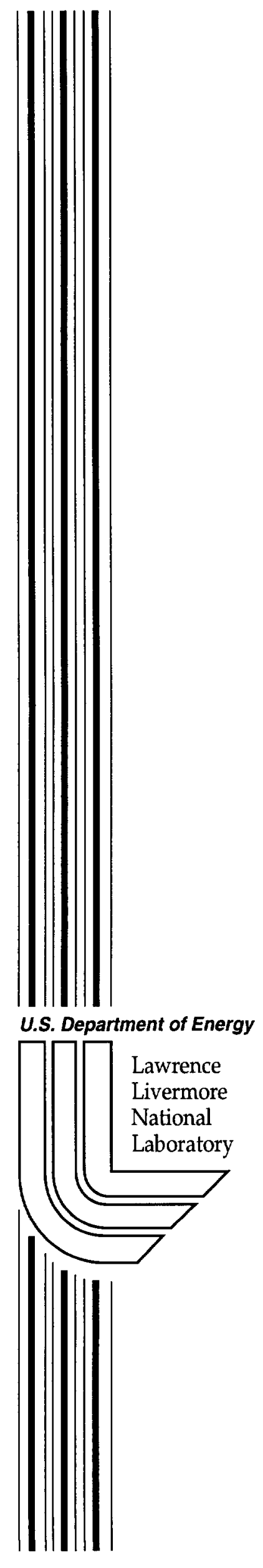

UCRL-ID-142596

\title{
Modeling of Laser Induced Damage in NIF UV Optics
}

\author{
M.D. Feit, A.M. Rubenchik
}

February 21, 2001 


\section{DISCLAIMER}

This document was prepared as an account of work sponsored by an agency of the United States Government. Neither the United States Government nor the University of California nor any of their employees, makes any warranty, express or implied, or assumes any legal liability or responsibility for the accuracy, completeness, or usefulness of any information, apparatus, product, or process disclosed, or represents that its use would not infringe privately owned rights. Reference herein to any specific commercial product, process, or service by trade name, trademark, manufacturer, or otherwise, does not necessarily constitute or imply its endorsement, recommendation, or favoring by the United States Government or the University of California. The views and opinions of authors expressed herein do not necessarily state or reflect those of the United States Government or the University of California, and shall not be used for advertising or product endorsement purposes.

This work was performed under the auspices of the U. S. Department of Energy by the University of California, Lawrence Livermore National Laboratory under Contract No. W-7405-Eng-48.

This report has been reproduced directly from the best available copy.

Available electronically at http://www.doe.gov/bridge

Available for a processing fee to U.S. Department of Energy and its contractors in paper from

U.S. Department of Energy

Office of Scientific and Technical Information

$$
\text { P.O. Box } 62
$$

Oak Ridge, TN 37831-0062

Telephone: (865) 576-8401

Facsimile: (865) 576-5728

E-mail: reports@adonis.osti.gov

Available for the sale to the public from

U.S. Department of Commerce

National Technical Information Service 5285 Port Royal Road Springfield, VA 22161

Telephone: (800) 553-6847

Facsimile: (703) 605-6900

E-mail: orders@ ntis.fedworld.gov

Online ordering: http://www.ntis.gov/ordering.htm

\section{OR}

Lawrence Livermore National Laboratory Technical Information Department's Digital Library http://www.llnl.gov/tid/Library.html 
Final report

\title{
Modeling of Laser Induced Damage in NIF UV Optics \\ Tracking number 00-ERD-066
}

\author{
Investigators: M.D. Feit (P.I.) \\ A.M. Rubenchik
}

\section{Introduction}

Controlling damage to nominally transparent optical elements such as lenses, windows and frequency conversion crystals on high power lasers is a continuing technical problem. Scientific understanding of the underlying mechanisms of laser energy absorption, material heating and vaporization and resultant mechanical damage is especially important for UV lasers with large apertures such as NIF. This LDRD project was a single year effort, in coordination with associated experimental projects, to initiate theoretical descriptions of several of the relevant processes.

In understanding laser damage, we distinguish between damage initiation and the growth of existent damage upon subsequent laser irradiation. In general, the effect of damage could be ameliorated by either preventing its initiation or by mitigating its growth. The distinction comes about because initiation is generally due to extrinsic factors such as contaminants, which provide a means of local laser energy absorption. Thus, initiation tends to be local and stochastic in nature. On the other hand, the initial damaging event appears to modify the surrounding material in such a way that multiple pulse damage grows more or less regularly. More exactly, three ingredients are necessary for visible laser induced damage. These are adequate laser energy, a mechanism of laser energy absorption and mechanical weakness. For damage growth, the material surrounding a damage site is already mechanically weakened by cracks and probably chemically modified as well. The mechanical damage can also lead to electric field intensification due to interference effects, thus increasing the available laser energy density.

In this project, we successfully accounted for the pulselength dependence of damage threshold in bulk DKDP crystals with the hypothesis of small absorbers with a distribution of sizes. We theoretically investigated expected scaling of damage initiation craters both to baseline detailed numerical simulations presently underway and to aid identification of damage initiators. Ancillary experimental techniques intended to yield information on laser energy absorption and shockwave generation were investigated. We also determined the role of material evaporation and fluid motion accompanying low-level CO2 laser energy absorption, which can potentially "heal" surface mechanical damage.

Section 2 of this report describes accomplishments of the project. Work reported elsewhere is mentioned briefly and cited. Section 3 describes the two 
proof of principle experiments carried out by UC collaborators. Section 4 has conclusions and recommendations for future work. Section 5 is a listing of reports and presentations arising from this project.

\section{Accomplishments}

\subsection{Damage initiation - nanoparticle absorption}

A leading hypothesis for the cause of damage initiation involves absorption by very small particles, which heat explosively, leading to plasma formation, material ablation for surface damage and generation of shockwaves. We carried through an analysis ${ }^{1}$ of this hypothesis with respect to observed ${ }^{2}$ bulk damage in deuterated KDP (DKDP) taking into account the initial absorption (Mie theory) by subwavelength sized particles, the effect of a distribution of particle sizes and the expected resultant dependence of observed damage fluence and obscuration on laser pulsewidth and energy. The reader is referred to [1] for details.

The novel aspect of this treatment is that absorbers of different sizes are most efficiently heated by pulses of different lengths. If a distribution in size of very small initiators exists, our model predicts a dependence on pulselength $\tau$ of damage threshold of form $\tau^{\mathrm{m}}$ where $\mathrm{m} \leq 0.5$. This prediction is in accord with LLNL experiments (Fig.(1)) and other results available in the literature. Combined with an independent observation of total beam obscuration, the model allows prediction of the smallest scale pinpoints contributing to damage (Fig.(2)). This is a significant result - the pulsewidth dependence of damage threshold is important both for understanding physics and for scaling experimental results from one regime to another.

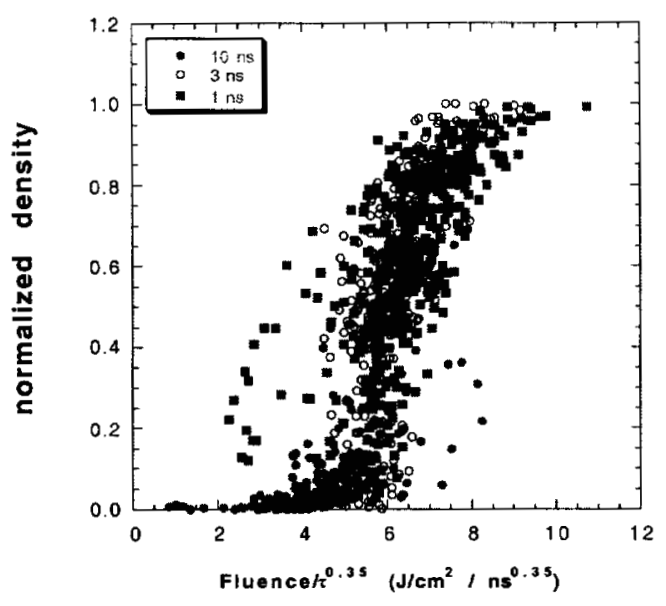

Fig. 1: Normalized observed DKDP damage incidence plotted as a function of fluence $/ \tau^{0.35}$ Curves for the three pulse durations are now quite similar

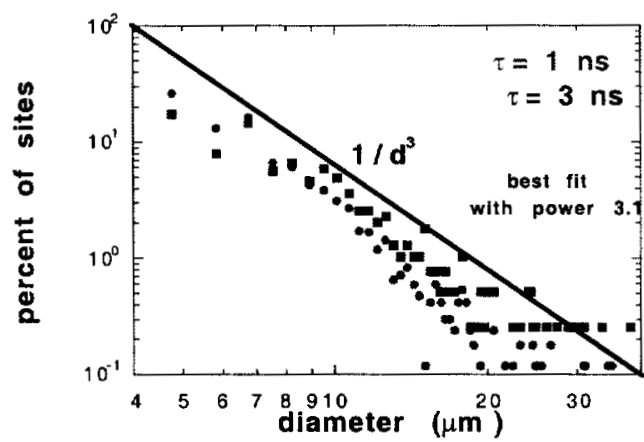

Fig. 2: Distribution by size of observed DKDP bulk damage sites contributing to obscuration at two pulselengths. Combined with independent measurement of obscuration, this 
allows determination of lower size cutoff value.

\subsection{Damage initiation - initiation crater scaling}

Operational UV energy fluences in high power lasers are generally many times smaller than those required for intrinsic dielectric breakdown. Thus, optics damage is expected to be initiated by structural and electronic imperfections such as inclusions, cracks, and defects.

Identification of these imperfections and processing modifications to eliminate them would improve the damage resistance of optics. This approach was successfully used some years ago when $\mathrm{Pt}$ inclusions were identified and eliminated from phosphate laser glass ${ }^{3}$. However, it is difficult to directly apply this approach to presently available high quality fused silica optics. It has been recognized ${ }^{4}$ that, at NIF level UV fluences, damage can be initiated by strongly absorbing inclusions as small as ten nanometers. In practice, it is very difficult to detect very small absorbing defects somewhere on a large surface at low concentration. Another possible damage initiator is a crack containing material resulting from the polishing process. In such a case, absorption or variation of refractive index is so small that the defects are nearly invisible.

Since UV light absorption by small absorbers results in a large energy density within a small volume, a microexplosion in the material results in an initiation crater. The resulting crater can be easily detected. Studies of these craters can aid determination of the identity of initiators. We theoretically and experimentally analyzed ${ }^{5}$ damage initiation crater structure scaling in fused silica and concluded that the observed damage is consistent with the presence of very small near surface absorbers. The reader is referred to ref.[5] for details of this study.

Laser damage crater formation was found to be similar to crater formation due to meteorite impact ${ }^{6}$ or to underground explosions $s^{7}$, We obtained crater size estimates as a function of deposited energy and the depth beneath the surface of the energy release. Experimental damage initiation craters in fused silica tend to have a fixed ratio of diameter to depth (Fig.(3) indicative of laser energy absorption very near the free surface. More exact extensive numerical simulations of crater formation are presently being carried out and will be reported in a future publication. In particular, the damage caused by the shockwave initiated by the damage event is being carefully modeled. 


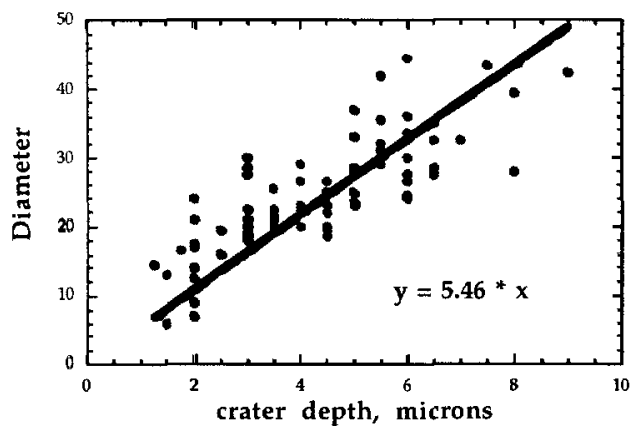

Fig.3: Measured diameter vs. depth ratio for craters produced by $3 \omega$ ( 351 $\mathrm{nm}$ ) radiation at fluence of $\sim 45 \mathrm{~J} / \mathrm{cm}^{2}$. The average aspect ratio (diameter to depth) is about 5.5

\subsection{Damage growth and mitigation}

Theoretical models for heating, evaporation, material flow, and stress and strain generation accompanying $\mathrm{CO} 2$ laser damage mitigation and surface treatment of fused silica are developed to aid understanding of scaling with process parameters. We find that lateral heat transport is an important cooling mechanism, more significant than evaporative cooling. Transverse conduction together with the increased thermal conductivity at high temperatures allows a gentle evaporation regime at low laser intensity in which the rate can be controlled via laser fluence. For higher laser intensity, recoil momentum imparted by rapid evaporation generates pressure, which can lead to transverse flow of the melted material. Only a very thin layer can flow because viscosity increases rapidly with depth. Evaporation and flow are subject to instabilities that can impact surface quality, especially. surface flatness, if large areas are processed. Analysis of stress indicates that maximal tensile stresses of order 0.1 $\mathrm{GPa}$, comparable to the tensile strength, can be generated

Recent experiments demonstrate that $\mathrm{CO}_{2}$ laser radiation is capable of efficiently removing damaged, absorbing material from damage initiation craters in fused silica. This processing results in a smooth crack free surface, and has great promise for use in damage mitigation. Issues of the amount of material, if any, which has to be removed to provide mitigation of subsequent laser damage growth, are being investigated. This is associated with the necessity of preserving the optical quality of the surface. Besides local mitigation of damage sites, the possibility of treating the entire surface of an optic is being investigated. The issue of optical quality of the resulting surface is paramount here. This approach was considered and rejected previously by D. Milam and H. Lowdermilk ${ }^{8}$, but recent experiments have suggested such treatment may be feasible. The analysis below includes some general conclusions regarding such surface treatment. 
In order to address these process issues, we attempt to understand the ablation mechanism, to evaluate the thickness and motion of the melt layer, to determine which laser parameters affect the ablation (evaporation) rate and the process sensitivity to parameter variations. We will show that $\mathrm{CW}$ laser irradiation produces a steady state temperature distribution due to lateral thermal transport. Evaporative cooling plays a small role in the case of gentle ablation. The temperature dependence of thermal transport coefficients is important in determining the scaling of ablation rate with laser power. We estimate below the sensitivity of the rate to variations of laser parameters in the gentle ablation regime.

Initial $\mathrm{CO}_{2}$ laser polishing experiments involved $\mathrm{CW}$ illumination of fused silica (pulse duration about $1 \mathrm{sec}$.) by low intensity radiation, $\mathrm{I} \sim 10^{4} \mathrm{~W} / \mathrm{cm}^{2}$. The refractive index of fused silica at the $\mathrm{CO}_{2}$ wavelength of $10.6 \mu \mathrm{m}$ was taken as $\mathrm{n}=2.24+0.1 \mathrm{i}$ (data for $\lambda=10.53 \mu \mathrm{m}){ }^{9}$ The radiation absorption length is small, $1_{\mathrm{abs}}=(2 \mathrm{k} \operatorname{Im}[\mathrm{n}])^{-1} \sim 8.4 \mu \mathrm{m}$ where $\mathrm{k}$ is the free space wavenumber. The absorption coefficient $\mathrm{A}$ for $10.6 \mu \mathrm{m}$ radiation on fused silica is about $85 \%$.

The glass temperature increases until high enough temperature is reached to start evaporation. We estimate the time $t$ to heat the surface up to temperature T. The energy density delivered by the laser up to this moment is AIt, where I is the light intensity. This energy is spent heating a layer with thickness on the order of the thermal diffusion length $l_{\mathrm{th}}=2 \sqrt{D t}$ up to temperature $T$. The thermal parameters of glass are functions of temperature, but for a temperature increase less than $1000^{\circ} \mathrm{C}$, the thermal parameters change by less than a factor of two. Therefore, we will use the room temperature values of thermal diffusivity $\mathrm{D}=0.01 \mathrm{~cm}^{2} / \mathrm{sec}$, and specific heat $\mathrm{c}=0.7 \mathrm{~J} / \mathrm{g}^{\circ} \mathrm{K}$ to make an estimate.

Heating the surface up to temperature $\mathrm{T}$ takes time $t_{\mathrm{h}}$

$$
t_{h}=\frac{4 D(\rho c T)^{2}}{(A I)^{2}}
$$

For a temperature $\mathrm{T}=1000^{\circ} \mathrm{C}, \mathrm{t}_{\mathrm{h}} \sim 1.3 \mathrm{msec}$. Hence, the silica must be processed with long pulses in the quasi-stationary regime.

Section I below evaluates the temperature distribution. Evaporation from the surface becomes important in the energy balance when the surface temperature is high enough. We estimate below the comparative roles of evaporative cooling and lateral thermal transport, and show that for the gentle ablation regime, the later is the dominant factor. We find that accurate evaluation of the evaporation rate must account for the temperature dependence of thermal conduction.

Section II evaluates the magnitude of hydrodynamic flow of the melted material due to the recoil momentum accompanying evaporation. The viscosity of the melt is high and increases rapidly with depth into the melt. We find a melt velocity on the order of $30 \mu \mathrm{m} / \mathrm{sec}$ at typical conditions and this velocity increases with laser beam size. 
The beneficial result of processing is due not only to removal of damaged material, but also to re-melting and healing of microcracks. To estimate the importance of this effect we need to know the melt depth, melt viscosity, and the melt motion. This homogenization of the surface is treated in Section 3. Finally, heating, melting and evaporation of glass produce thermal stresses and strains. Section 4 of this memo analyzes their magnitude.

In the conclusion, we discuss the prospects for $\mathrm{CO}_{2}$ laser damage mitigation, possible mitigation schemes, advantages and pitfalls.

\subsubsection{Temperature distribution and evaporation during processing}

The typical laser spot size used in damage mitigation is much larger than the radiation absorption length so it is natural to start with a one-dimensional thermal model. The temperature distribution is determined by the heat equation

$$
\frac{\partial T}{\partial t}=D \frac{\partial^{2} T}{\partial x^{2}}+Q ; \quad Q=\frac{A I}{\rho c l_{a b s}} e^{-\frac{x}{l_{a b s}}}
$$

We assume the laser is turned on at time $t=0$. At low intensity, when the surface temperature is well below the critical point, a large energetic difference exists between the solid and gaseous phases. The position $Z(t)$ of the evaporation front is determined by the phase transition kinetic and energy balance. It is important to note that the Stefan model is not applicable for laser ablation since the temperature at the evaporation front is not fixed, but must be determined selfconsistently. The velocity of the evaporation front is given by a relation of form ${ }^{10}$

$$
V=\frac{d Z}{d t}=V_{0} e^{-\frac{U}{T_{s}}}
$$

Here $\mathrm{U}$ is the latent heat of evaporation per atom, $3.6 \mathrm{eV}$ for glass, and $\mathrm{T}_{\mathrm{s}}$ the surface temperature. The constant $V_{0}$ is determined by the kinetics of the flow in the Knudsen layer near the surface, but its value is of order of the sound speed in the condensed phase[3]. Equation (1.1) must be solved with the boundary condition at the evaporation front:

$$
k \frac{\partial T}{\partial x}=\left.V \Delta H\right|_{x=Z(t)}
$$

Here $\mathrm{k}$ is the thermal conduction coefficient, and $\Delta H$ is the difference in enthalpies of the gaseous and condensed phases. Approximately

$$
\Delta H=L_{e}+L_{m}+\rho c T
$$

Here $\mathrm{L}_{\mathrm{e}}$ and $\mathrm{L}_{\mathrm{m}}$ are latent heats of evaporation and melting, respectively. Typically $\mathrm{L}_{\mathrm{e}}$ is much larger than all the other terms in Eq.(1.4). The system of 
equations (1.1-1.3) for constant illumination I has a steady-state solution, the stationary evaporation wave[3]. The shape of the temperature profile is shown in Fig.(4).

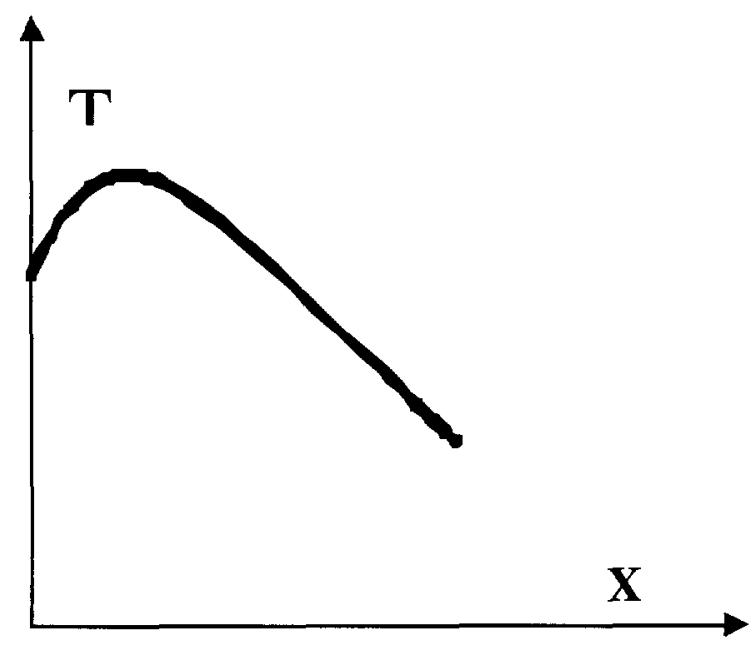

Fig 4 : Temperature profile for stationary evaporation rate. Evaporation front is located at $\mathrm{x}=0$.

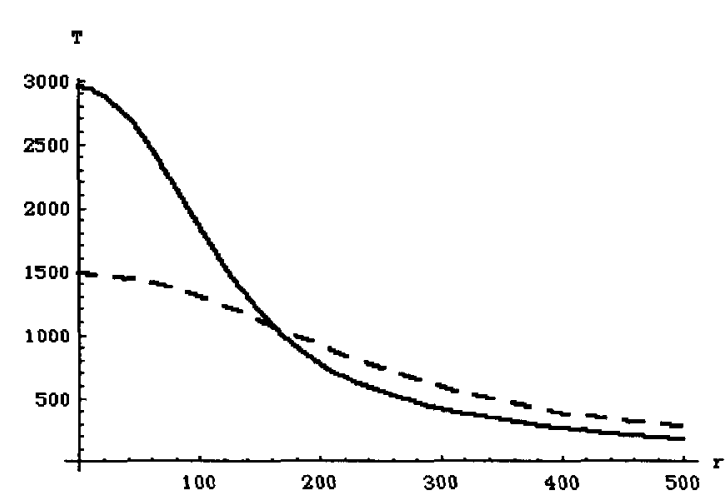

Fig. 5 : Steady state transverse temperature distribution due to $\mathrm{CO}_{2}$ laser irradiation at fixed power $3 \mathrm{~W}$. Solid line corresponds to a Gaussian beam with radius of $100 \mu \mathrm{m}$, dashed line to radius of $200 \mu \mathrm{m}$. Temperature is in ${ }^{\circ} \mathrm{K}$, radius in $\mu \mathrm{m}$.

An interesting feature of this distribution is that the temperature has its maximum inside the glass surface, at a depth of about $l_{\text {abs }}$ from the evaporation surface. The surface temperature is lower than the maximum temperature due to evaporative cooling.

In the steady-state evaporation wave, energy balance determines the surface temperature and the evaporation rate. The absorbed energy is spent to advance the evaporation front according to

$$
A I=V \Delta H=V_{0} e^{-\frac{U}{T_{s}}}\left(L_{e}+\rho c T_{s}\right)
$$

For the evaporation rate we have a first estimate

$$
\mathrm{V} \sim \mathrm{AI} / \mathrm{L}_{\mathrm{e}}
$$

The evaporation energy for $\mathrm{SiO}_{2}$ molecules is about $1.310^{4} \mathrm{~J} / \mathrm{cm}^{3}$. If we include the dissociation of $\mathrm{SiO}_{2}$ molecules during evaporation, the energy increases to $310^{4} \mathrm{~J} / \mathrm{cm}^{3}$. 11 . The evaporation energy per molecule $\mathrm{U}$ is $3.6 \mathrm{eV}$. At laser intensity of $10 \mathrm{KW} / \mathrm{cm}^{2}$, the evaporation velocity is $0.3 \mathrm{~cm} / \mathrm{sec}$. This value is larger than the experimentally observed material removal rate. The reason for 
this discrepancy is the effect of lateral thermal transport, which was neglected in the 1D model of Eq.(1.1). For a pulse duration of $1 \mathrm{sec}$, the thermal diffusion length is about $2 \mathrm{~mm}$ which is much larger then the laser spot size. Lateral thermal transport limits temperature growth so that temperature reaches a stationary value smaller than that given by solution of (1.5). For a Gaussian beam of radius a, the temperature in the center of the laser spot is

$$
T_{s}=\frac{A I \sqrt{\pi}}{2 \kappa} a=\frac{A P}{2 \sqrt{\pi} \kappa a}
$$

where $P$ is the laser power. This shows how, at constant power, the steady state temperature decreases as the laser spot size is increased.

The stationary temperature distribution over the spot is given by the formula

$$
T(r)=\frac{A I a^{2}}{\kappa} \sqrt{\frac{D}{\pi}} \int_{0}^{\infty} \frac{\exp \left[-\frac{r^{2}}{a^{2}+4 D t}\right]}{\left(a^{2}+4 D t\right) \sqrt{t}} d t=\frac{A I a}{\kappa \sqrt{\pi}} \int_{0}^{\infty} \frac{\exp \left[-\frac{\left(\frac{r}{a}\right)^{2}}{1+p^{2}}\right]}{1+p^{2}} d p
$$

Temperature profiles at fixed laser power of $3 \mathrm{~W}$ for two different beam radii are shown in Fig.[5]. Temperature at the spot center changes in proportion to the beam radius. For a power of $30 \mathrm{~W}$, the spatial scales in the figure must be stretched by a factor of 10 , so the beam radii would be 1 and $2 \mathrm{~mm}$, respectively.

A steady state temperature distribution is not reached for a few thermal times the thermal diffusion time of $\tau=a^{2} / 4 D$. Nonstationarity can be important for mitigation of large spots. For example, we note that in experiments with spot diameter of $3.3 \mathrm{~mm}$, irradiation for $1 \mathrm{sec}$. produced no visible surface modification. However, irradiation for $60 \mathrm{sec}$. with the same power produced a crater 50 microns deep ${ }^{12}$. The thermal time $\tau$ is about $0.7 \mathrm{sec}$ for this experiment; at the end of a 1 second pulse, the surface temperature is about 0.5 of its maximal value at infinite time. Because the ablation rate is very sensitive to temperature, the qualitatively different results of the two experiments are natural.

If this temperature is lower than the value found by solution of Eq.(1.5), evaporative cooling is not important and one can substitute the temperature given by Eq.(1.7) into Eq.(1.2) to estimate the evaporation rate. This number, however, is not very reliable because the thermal conduction coefficient is a strong function of temperature. The evaporation rate, in turn, is very sensitive to temperature variations so the thermal problem must be solved with high accuracy. Some general conclusions can be drawn, however, without specific knowledge of the thermal distribution. 
First, evaporation, in the regime where lateral transport is important, is sensitive to variations of laser intensity and laser spot size. In LLNL experiments [5], removal rates of about $50 \mu \mathrm{m} / \mathrm{sec}$ were observed. Using a value of $6 \mathrm{~km} / \mathrm{sec}$ for $\mathrm{V}_{0}$, we find the ratio $\mathrm{T}_{\mathrm{s}} / \mathrm{U}$ to be about 0.05 . Thus, $\mathrm{T}_{\mathrm{s}}$ is about $2245^{\circ} \mathrm{K}$ and not sensitive to the exact value of the ablation rate. To increase the ablation rate by a factor of $e$, it is sufficient to increase the temperature by $\Delta \mathrm{T}$ where

$$
\frac{\Delta T}{T_{s}}=\frac{T_{s}}{U} \approx 0.05
$$

Such an increase can be produced by a $5 \%$ variation in intensity or beam radius.

On the other hand, in this regime lateral transport smoothes beam inhomogeneities, and the surface temperature profile is broader than the intensity distribution.

At the low ablation rates observed in initial experiments [5], only the peak of the temperature distribution causes significant evaporation. Expanding (1.7) for small $r$ we have

$$
T(r)=T_{s}\left(1-r^{2} / 2 a^{2}\right)
$$

Substituting (1.8) into the evaporation rate Eq.(1.2), we find that the evaporation rate has a Gaussian profile

$$
V(r)=\mathrm{V}_{0} e^{-\frac{U}{T_{s}}} e^{-\frac{U}{T_{s}} \frac{r^{2}}{2 a^{2}}}
$$

Since the crater depth is equal to the evaporation rate times the pulse duration, we expect the mitigation crater to have a Gaussian shape with radius $R=\sqrt{\frac{2 T_{s}}{U}} a$. For the above parameters, the crater radius is found to be 3 times smaller than the beam radius.

The above estimate indicates that a smooth mitigation crater is expected for a range of parameters. For low beam power, the evaporation rate will be too low for material removal, while at high power the rate is too high to control the amount removed. Fig.(6) shows the calculated ablation rate in $\mu \mathrm{m} / \mathrm{sec}$ as a function of power for a $2 \mathrm{~mm}$ beam. 


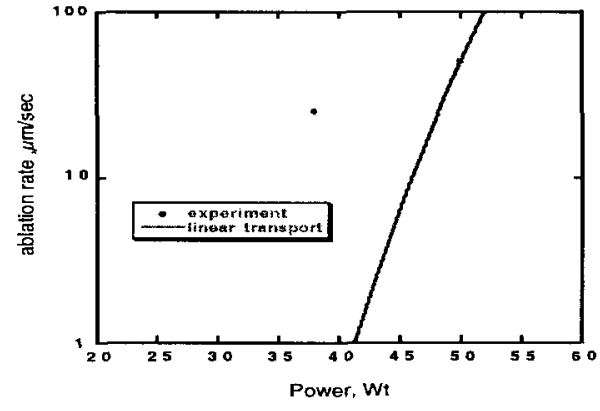

Fig.6: Calculated ablation rate vs. power for laser beam with diameter $2 \mathrm{~mm}$. The constant thermal conductivity was chosen to fit the calculated ablation rate at $50 \mathrm{~W}$ with the experimental data.

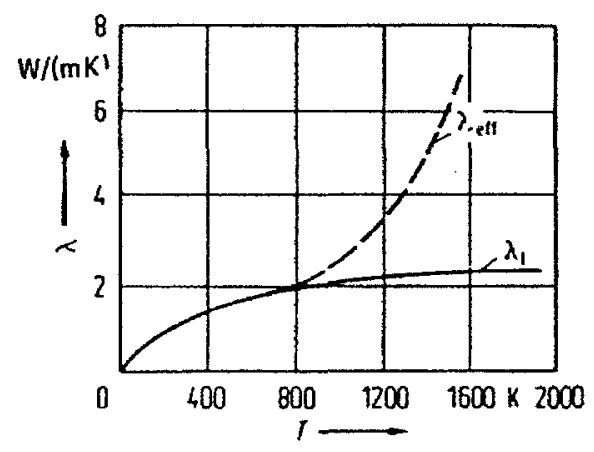

Fig.7: Temperature dependence of thermal conductivity $\lambda$ of $\mathrm{SiO} 2$ glass. $\lambda_{1}$ : pure thermal conductivity; $\lambda_{\text {eff }}$ : total heat transport. From. Ref[13].

Now we discuss the experimental data. In recent experiments [12], a $\mathrm{CO}_{2}$ laser with power $50 \mathrm{~W}$ etched a crater with diameter $1.3 \mathrm{~mm}$ and depth 50 microns during $1 \mathrm{sec}$. According to the above estimate, the beam radius must be about $2 \mathrm{~mm}$. If we use the value $\kappa=0.02 \mathrm{~W} / \mathrm{cm}^{\circ} \mathrm{K}$ for glass thermal conductivity, the temperature $T_{s}$ is about $3000 \mathrm{C}$. At first glance, such high temperature indicates that evaporative cooling plays an important role. But the value of conductivity just used is the value corresponding to temperature $800^{\circ} \mathrm{K}$ (Fig.(7). At higher temperatures, radiation transport plays an important role and the effective thermal conductivity increases. For example, at $\mathrm{T}=1600^{\circ} \mathrm{K}$, the effective thermal conduction is 3.5 times larger than the value at $800^{\circ} \mathrm{K}$ [13]. The increase of thermal conductivity, and therefore transverse losses, with surface temperature limits the temperature rise. To be consistent with experimental observations, it is sufficient that the surface temperature be reduced to $2245^{\circ} \mathrm{K}$.

The constant value of thermal conductivity used in the calculations presented in Fig.(6) was adjusted to fit the experimental data at $\mathrm{P}=50 \mathrm{~W}$. It is important to note that at this rate, evaporative cooling plays a small role in the total temperature balance and the evaporation rate can be found from the solution of the nonlinear stationary thermal problem. The experimental crater etched in the glass is a few times smaller than the beam size as predicted by the model above.

In a second set of experiments, the laser power was decreased to $37.5 \mathrm{~W}$. The crater depth in this case was $25 \mu \mathrm{m}$ and the diameter was about $1 \mathrm{~mm}$. The results shown in Fig.(6) are inconsistent with experiment, the predicted ablation being much smaller. The strong calculated ablation rate temperature dependence is evidence of the importance of nonlinear thermal conduction in setting the evaporation rate. 
Let us estimate the effect of nonlinear conduction. The exact solution of the nonlinear problem is difficult. Also data on the temperature dependence of the thermal parameters are not available. Hence, we can make only a semiquantitative estimate.

Consider a model problem in which energy is absorbed on the surface of a spherical dimple with radius a. If the material boundary is thermally insulated, the problem is spherically symmetric and can be simply evaluated. If the laser irradiates the dimple with constant power $P$, and the thermal conduction is independent of temperature, a stationary temperature distribution develops with temperature on the dimple surface of

$$
\mathrm{T}=\mathrm{AP} / 2 \mathrm{a} \pi \mathrm{K}
$$

This expression has the same structure as Eq.(1.6) differing from it only by a numerical factor of about 1.7. Consider now the temperature dependent thermal conduction. The stationary temperature distribution is given by the equation

$$
\frac{1}{r^{2}} \frac{d}{d r} \kappa(T) r^{2} \frac{d T}{d r}=0
$$

with the boundary condition

$$
-\left.2 \pi r^{2} \kappa(T) \frac{\partial T}{\partial r}\right|_{r=a}=P
$$

For simplicity, we assumed that the product $\rho c$ is independent of temperature. The solution at $r=a$ of Eq.(1.9) with boundary condition Eq.(1.10) is given by

$$
\mathrm{u}(\mathrm{T})=\frac{\mathrm{P}}{2 \pi \mathrm{a}} \quad ; \quad \mathrm{u}(\mathrm{T})=\int \kappa(\mathrm{T}) \mathrm{dT}
$$

Detailed information on the temperature dependence of the thermal conductivity of fused silica is not available. The thermal conductivity increases from $\sim 1 \mathrm{~W} / \mathrm{m}^{\circ} \mathrm{K}$ at room temperature to $2 \mathrm{~W} / \mathrm{m}^{\circ} \mathrm{K}$ at $800^{\circ} \mathrm{K}$ and then up to 7 $\mathrm{W} / \mathrm{m}^{\circ} \mathrm{K}$ at $1600^{\circ} \mathrm{K}$. [13]. No data is available for higher temperatures. Also, at temperatures over $800^{\circ} \mathrm{K}$, radiative transport dominates conventional thermal conduction and contributes to an effective thermal conductivity. See Fig.[7]. Due to these uncertainties, we will consider the simplest model, a linear temperature dependence of conductivity. We take

$$
\kappa(T)=\kappa_{0}\left(1+2.5\left(\frac{T-T_{0}}{T_{0}}\right)\right) ; \quad T_{0}=800 K
$$

The numerical coefficients are chosen to match the conductivity data at $800^{\circ} \mathrm{K}$ and $1600^{\circ} \mathrm{K}$. For the above conductivity, the temperature is 


$$
T=0.6 T_{0}+\left(\frac{P}{4.25 \kappa_{0} a}\right)^{1 / 2}
$$

By substituting Eq.(1.12) into Eq.(1.6), we can calculate the ablation rate. The comparison of ablation rate as calculated using linear and nonlinear temperature conduction is shown in Fig.(8). One sees that even our simple model presents a reasonable description of the experimental data and can help guide experiments. For example, the dependence of rate on power will be steeper for smaller beams.

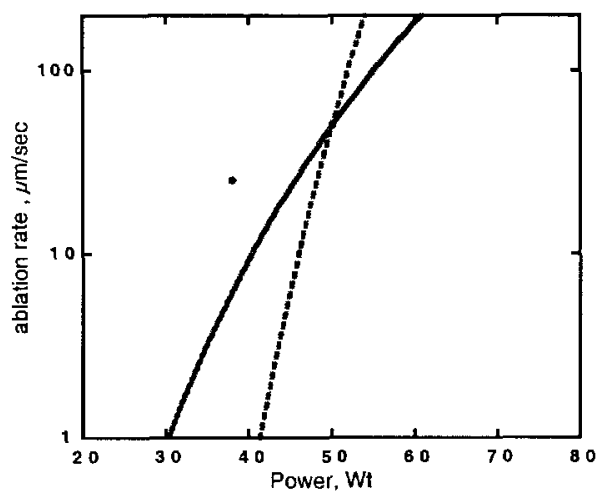

Fig.8: Comparison of ablation rates calculated with linear and nonlinear thermal transport. Dots are experimental values. Parameters are the same as in Fig.6

Finally, consider the interaction of laser radiation with vapor. From the above estimates, it follows that for the observed ablation rates, the surface temperature is well below the boiling point. In this case, the vapor pressure is much less than atmospheric. Even if the vapor were ionized, the vapor density is so low that laser absorption in the vapor will be a negligible loss mechanism.

\subsubsection{Melted layer and its outward flow}

If the glass surface is heated over $2000^{\circ} \mathrm{C}$, a surface layer of material is melted. On the one hand, the melt can heal micro-cracks thus improving the damaged glass structure. But on the other hand, the hydrodynamic motion of the melt due to pressure caused by momentum transfer from evaporation can adversely affect the surface quality.

Amorphous fused silica has no phase transition between solid and liquid states. Continuous transition between the solid and liquid occurs due to changes in viscosity. The viscosity of even high temperature glass is very high. This high viscosity prevents devitrification and makes it possible to cool to room 
temperature without crystallization. The viscosity is a very strong function of temperature so temperature distribution is very important.

The steady state temperature distribution along the axis of the laser spot as a function of depth $z$ is given by

$$
T=T_{0} \frac{2 a}{\pi} \sqrt{D} \int_{0}^{\infty} \frac{e^{\frac{-z^{2}}{4 D t}}}{\sqrt{t}\left(a^{2}+4 D t\right)} d t
$$

Here $T_{0}$ is the temperature at the center on the surface, $\mathrm{a}$ is the beam radius, and $z$ is the distance from the surface. Introducing the dimensionless variable $\mathrm{x}=\mathrm{a}^{2} / 4 \mathrm{Dt}$ one can rewrite $(2.1)$ as

$$
T=\frac{T_{0}}{\pi} \int_{0}^{\infty} \frac{e^{-\frac{z^{2} x}{a^{2}}}}{(x+1) \sqrt{x}} d x
$$

Even without further calculation, one sees that the depth of the melt will be about equal to the spot size. The shape of the profile is independent of thermal conductivity, which does, however, determine $\mathrm{T}_{0}$. Evaluating the integral gives

$$
T(z)=T_{0} e^{\left(\frac{z}{a}\right)^{2}} \operatorname{erfc}(z / a)
$$

This temperature distribution is shown in Fig.(9)

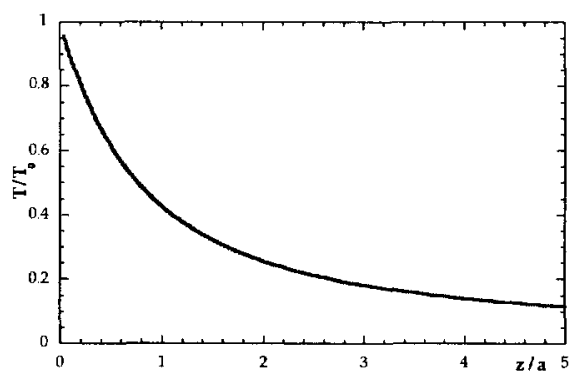

Fig.9: Temperature distribution beneath the surface along the axis of the laser beam. $z$ is distance from the surface, $a$ the spot radius. For $\mathrm{z}>>\mathrm{a}$, temperature drops as $1 / \mathrm{z}$.

Near the surface, the temperature drops linearly 


$$
T=T_{0}\left(1-\frac{2}{\sqrt{\pi}} \frac{z}{a}\right)
$$

For a typical case when the surface temperature $T_{0}$ is not very much higher than the melt temperature $T_{m}$, we find the thickness of the melted layer $h$ as

$$
h=a \frac{\sqrt{\pi}}{2} \frac{T_{0}-T_{m}}{T}=0.9 a \frac{T_{0}-T_{m}}{T}
$$

Evaporation from the heated surface not only cools the surface but also generates recoil momentum, which can move the melt. The pressure on the surface P created by evaporation is given by the phenomenological expression [4]

$$
P=P^{*} \exp \left[U\left(\frac{1}{T_{b}}-\frac{1}{T_{s}}\right)\right]
$$

where $\mathrm{U}=3.6 \mathrm{eV}$ is the evaporation energy per molecule, $\mathrm{T}_{\mathrm{b}}$ the boiling temperature, $\mathrm{T}_{\mathrm{b}} \sim 2540 \mathrm{~K}$ for silica, and $\mathrm{P}^{*} \sim 0.1 \mathrm{MPa}$. This equation can be used as a definition of the boiling temperature, i.e. the temperature where vapor pressure equals $0.1 \mathrm{Mpa}=1 \mathrm{~atm}$. For a beam center surface temperature $\mathrm{T}_{\mathrm{s}}-2245^{\circ} \mathrm{K}$, the pressure $\mathrm{P}_{0} \sim 0.012 \mathrm{MPa}$.

From Eq.(1.8), the temperature distribution has a parabolic profile near the spot center,

$$
\mathrm{T}(\mathrm{r})=\mathrm{T}_{\mathrm{s}}\left(1-\mathrm{r}^{2} / 2 \mathrm{a}^{2}\right)
$$

and the pressure has a Gaussian profile with radius $R=\sqrt{\frac{2 T_{s}}{U}} a$, the same profile as for the evaporation rate

$$
P(r)=P_{0} e^{-\frac{U r^{2}}{2 T_{s} a^{2}}}
$$

The pressure also has a parabolic profile near the center:

$$
P(r)=P_{0}\left(1-\frac{U r^{2}}{2 T_{s} a^{2}}\right)
$$

Hydrodynamic motion of the melt can be treated as a viscous flow of incompressible liquid. The magnitude of viscosity is important to estimate the flow parameters. In the range $1600-2000^{\circ} \mathrm{C}$, viscosity is given by the expression ${ }^{14}$ 


$$
\eta=1.05^{*} 10^{-10} e^{\frac{E}{T}}
$$

where $E$ is an activation energy, $E \sim 6.44 \mathrm{eV}$. We will use this expression for slightly higher temperatures. The activation energy $E$ in (2.7) is higher than the evaporation energy $U$. This expression was derived for pure fused silica used in optical fibers with $\mathrm{OH}$ and transition metal ion content of less than $1 \mathrm{ppbw}$. Increased $\mathrm{OH}$ and ion content typically decreases both activation energy and viscosity. Near the surface, at the beam center, at temperature of $\mathrm{T}=2245^{\circ} \mathrm{K}$, the viscosity $\eta_{0}=180000$ poise. The temperature drops linearly with depth so the viscosity increases exponentially:

$$
\eta=\eta_{0} e^{\frac{2 E z}{T_{0} \sqrt{\pi} a}} ; \quad \eta_{o}=1.05 * 10^{-10} e^{\frac{E}{T_{0}}}
$$

For the parameters given above, the e-folding length for viscosity is $h \sim a \sqrt{ } T_{0_{-}} / 2 \mathrm{E} \sim 0.03 \mathrm{a}$. The melt is thus a very viscous liquid. For comparison, the viscosity of water is 0.01 poise

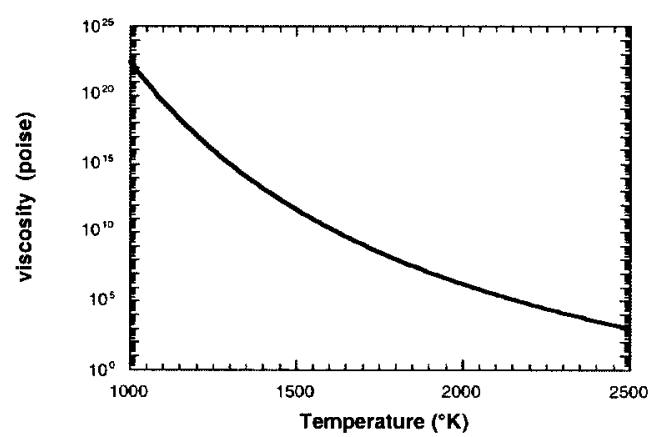

Fig. 10: Calculation of viscosity of fused silica according to Eq.(2.7). Note variation over 20 orders of magnitude for a $1000^{\circ}$ temperature change.

Now consider the melt motion under the effect of the pressure due to evaporation. We will see that the melt velocity will be slow so we can disregard nonlinear terms. Also we can treat the motion as stationary.

Since the melt thickness is much smaller then the spot radius, the derivatives of velocity with respect to $z$ are much larger than the transverse derivative with respect to radius. From the continuity equation, we see that the vertical component of velocity $\mathrm{v}_{\mathrm{z}}$ is much smaller than the radial component $\mathrm{v}_{\mathrm{r}}$. We can thus write the $\mathrm{z}$ and $\mathrm{r}$ components of the Euler equations as follows:

$$
\frac{\partial p}{\partial z}=0
$$




$$
\frac{\partial}{\partial z} \eta \frac{\partial}{\partial z} v_{r}=\frac{\partial p}{\partial r}
$$

The continuity equation completes the problem description

$$
\frac{\partial}{r \partial r} r v_{r}+\frac{\partial v_{z}}{\partial z}=0
$$

Consider first the melt motion in a layer of thickness $h$ assuming constant viscosity. The boundary conditions on the melt boundary at $z=0$ and on the free surface at $\mathrm{z}=\mathrm{h}$ are

$\mathrm{v}_{\mathrm{z}}=0, \mathrm{v}_{\mathrm{r}}=0$ at $\mathrm{z}=0$

and

$$
v_{z}=-u ; \quad \frac{\partial v_{r}}{\partial z}=0 ; \quad p=P(r) \quad \text { at } \mathrm{z}=\mathrm{h}
$$

Here $\mathrm{u}$ is the vertical velocity of the melt front. Integrating (2.10) we have

$$
v_{r}=\frac{z(z-2 h)}{2 \eta} \frac{\partial p}{\partial r}
$$

Integrating (2.11) and using the boundary conditions we have

$$
u=-\frac{1}{2 \eta r} \frac{\partial}{\partial r} r \frac{\partial P}{\partial r} \int_{0}^{h} z(z-2 h) d z=\frac{h^{3}}{3 \eta r} \frac{\partial}{\partial r} r \frac{\partial P}{\partial r}
$$

One sees that for a parabolic pressure profile (e.g. Eq.(2.6)), $\mathrm{u}$ is independent of $\mathrm{r}$ so the central part of the spot remains flat during the movement of the melt front. For Eq.(2.6) we find velocity

$$
u=\frac{2 h^{3} U}{3 \eta T a^{2}} P_{0}
$$

Unfortunately, this simple model, which would be appropriate for a simple melt, is inadequate in our case. The problem is the neglect of increased viscosity with depth.

We therefore consider the model in which viscosity grows exponentially with depth into the melt, as given by Eq.(2.8). 


$$
\eta=\eta_{0} e^{\frac{2 E z}{T_{0} \sqrt{\pi} a}}=\eta_{0} e^{\frac{z}{b}}
$$

Again we place the free surface at $\mathrm{z}=0$ and consider an infinitely deep liquid. Integrating Eq.(2.10) over $\mathrm{z}$ we have

$$
v_{r}=\frac{b^{2}(z / b-1) e^{\frac{z}{b}}}{2 \eta_{0}} \frac{\partial p}{\partial r}
$$

Integration of the continuity equation (2.11) then provides the surface velocity $u$

$$
u=-2 \frac{b^{3}}{\eta_{0} r} \frac{\partial}{\partial r} r \frac{\partial P}{\partial r}=\frac{4 b^{3} U}{\eta_{0} T a^{2}} P_{0}=\frac{\pi^{3 / 2} a T^{2} U}{2 \eta_{0} E^{3}} P_{0}
$$

This expression looks similar to (2.14), but the effective depth is much smaller than $h$. As a result, the melt velocity $u$ for the above parameters is now only about $1.7 \mu \mathrm{m} / \mathrm{sec}$ and is much less than the observed rate of evaporation of about $50 \mu \mathrm{m} / \mathrm{sec}$.

Thus far, we have discussed experiments involving large spots and long pulses. Experiments were also carried out with beams having diameters about $0.6 \mathrm{~mm}$ and with shorter pulselengths. In these experiments, ablation rates were higher, up to $500 \mu \mathrm{m} / \mathrm{sec}$. As a result, a higher surface temperature of about 2560 ${ }^{\circ} \mathrm{K}$ was reached. At this higher temperature, the viscosity drops to 4800 poise and the melt velocity $u$ was calculated to be about $130 \mu \mathrm{m} / \mathrm{sec}$ comparable to the observed ablation rate. The crater edges in this case have pronounced raised rims produced by flow from the crater. An illustrative comparison of shapes of low and high ablation rate craters is presented in Fig.(11)

Note that the melt velocity increases with the beam size. This implies that for large beams melt motion and subsequent surface deformation can be a problem. Our estimates above used viscosity data for pure fused silica. Viscosity might be smaller for our actual material. Also, viscosity and melt motion are even more sensitive to temperature increases than is the evaporation rate. Any increase in surface temperature will greatly enhance the role of material flow. 


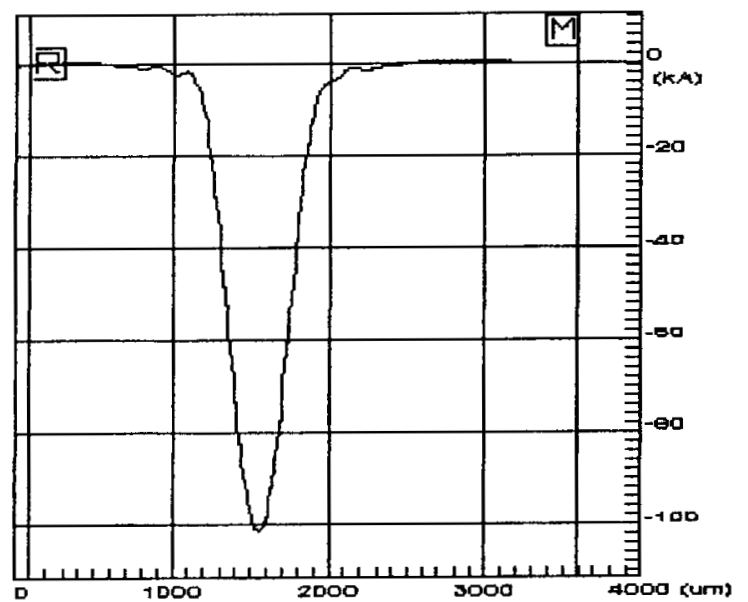

Fig. 11(a): Crater produced by $60 \mathrm{sec} 50$ W large beam exposure. Ablation rate $0.5 \mu \mathrm{m} / \mathrm{sec}$. From [ ${ }^{15}$.

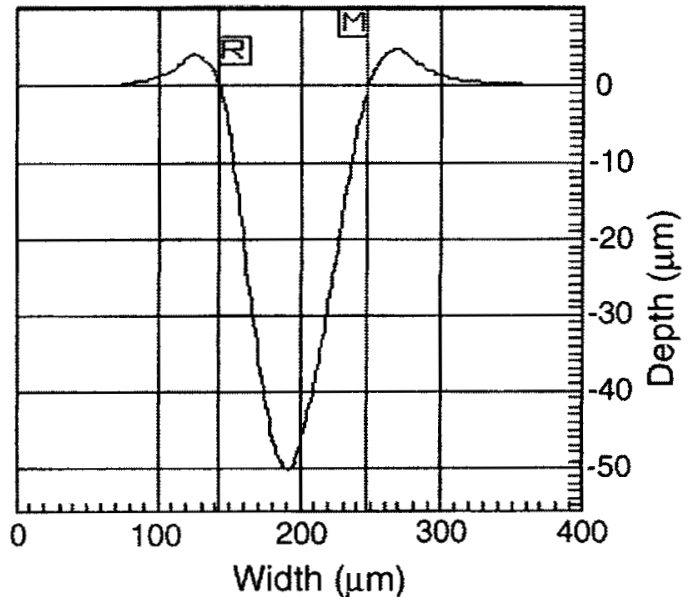

Fig. 11(b): Crater produced by $0.1 \mathrm{sec} 1$ W exposure with $0.6 \mathrm{~mm}$ diameter beam. Ablation rate $500 \mu \mathrm{m} / \mathrm{sec}$. Note rim. From $\left.{ }^{[6}\right]$.

\subsubsection{Thermal homogenization of surface}

One possible method of damage mitigation is thermal healing of cracks and smoothing of surface inhomogeneities. This requires hydrodynamic flow as discussed in Section 2. Additionally, evaporation induced surface perturbations can relax after pulse termination and before freezing of the melt.

Smoothing of the melted surface takes place due to surface tension. The surface tension $\sigma$ for glass is about $300 \mathrm{dyne} / \mathrm{cm}^{17}$ and not sensitive to the temperature. For surface relief given by $z=\zeta(x, y)$, the pressure variation is given by

$$
p=\sigma \Delta \zeta
$$

If the typical surface corrugation scale is larger then the melt depth, the time for smoothing can be estimated by substitution of (Eq.3.1) into Eq.(2.15), and taking into account that $u=\frac{\partial \zeta}{\partial t}$. For corrugations with scale 1 , we find smoothing time $\tau$ of

$$
\tau \approx \frac{\eta_{0} l^{4}}{\sigma b^{3}}
$$

For corrugation of scale $1 \sim \mathrm{a}$ and the above parameters, $\tau \sim 3^{*} 10^{5} \mathrm{~s}$, much longer than the cooling time. This means large-scale corrugations produced during processing cannot be smoothed.

At the other extreme, we now consider small-scale corrugations, i.e. much smaller than the melt depth. For example, these might be microcracks. In this 
case, the melt can be treated as an infinitely deep viscous liquid. The smoothing time for a small crack of scale 1 can be estimated from dimensional arguments (for exact calculations see Appendix A)

$$
\tau \sim \frac{\eta l}{\sigma}
$$

For 1 of $1 \mu \mathrm{m}$ and temperature $\mathrm{T}=2245^{\circ} \mathrm{K}$, the viscosity $\eta=\eta_{0}$ the smoothing time on the surface is small, about $60 \mathrm{msec}$. Below the surface, the viscosity is still about $\eta=\eta_{0}$ within a layer of thickness $b \sim 0.03 a$. For a beam radius of $1 \mathrm{~mm}$, the melt thickness is larger than the size of the surface damage layer created by polishing.

It is thus very reasonable to treat local damage spots by not only removing damaged material, but also by healing small cracks in the remaining material.

As noted in the introduction, it seems very desirable to extend laser processing from local sites to treatment of the entire surface since melting of the surface layer can heal microcracks. However, to maintain surface flatness, the surface temperature must be low enough that the evaporation rate is small, less than, say, $10 \mathrm{~nm} / \mathrm{sec}$. From Eq.(1.2), the surface temperature must then be lower than $1550^{\circ} \mathrm{K}$ and viscosity will be about $4.610^{10}$ poise. This implies that it will be extremely difficult to heal microcracks in the surface without significantly modifying surface flatness.

\subsubsection{Thermal strains and stresses induced by $\mathrm{CO}_{2}$ polishing}

The laser heated glass generating stress and strain due to thermal expansion. These strains can distort the initial flat glass surface thus degrading the optical quality. Stresses can cause the glass to fail, producing cracks which act as centers for subsequent damage growth.

One sees that if the heating of the glass is stationary, i.e. $v<D / a$ where $v$ is the scan velocity and $D$ the thermal diffusivity, the time for buildup of stresses is $\tau_{\sigma} \sim \mathrm{a} / \mathrm{s}$ ( $\mathrm{s}$ is the sound speed). This time is much smaller than the time to scan over the spot $\mathrm{a} / \mathrm{v} \sim \mathrm{a}^{2} / \mathrm{D}$. In this regime, stresses and strains can be treated as stationary.

To make an estimate, consider a model spherically symmetrical temperature distribution $T(r)$. At large $r$, the heat equation gives $T \sim T_{0} a / r$. The temperature gradually drops from $\mathrm{T} \sim \mathrm{T}_{0}$ at the spot center with spatial scale $\sim \mathrm{a}$. The material displacement $u$ in this case has only a radial component $u_{r}(r)=u(r)$ given by

$$
u=\alpha \frac{1+v}{3(1-v)} \frac{1}{r^{2}} \int_{0}^{r} T(r) r^{2} d r
$$


Here $\alpha=7^{*} 10^{-7} \mathrm{~K}^{-1}$ is the thermal expansion coefficient, $v=0.17$ is the Poisson ratio. The maximum displacement occurs at $r \sim a$ where $u \sim$ Ta. That is, the displacement is proportional to the spot size. For $\mathrm{T} \sim 2000^{\circ} \mathrm{K}$ and $\mathrm{a}=1 \mathrm{~mm}$, this displacement is about $1 \mu \mathrm{m}$. The residual deformation remaining after the glass freezes can be expected to be of the same order because of the high viscosity. It is clear that deformations of this scale can seriously affect the part's optical quality. The danger to surface quality for large area scanning is apparent.

The resulting strains and stresses can be calculated from the above displacement $\mathrm{u}$

Strains

$$
\begin{aligned}
& u_{\theta \theta}=u_{\varphi \varphi}=\frac{u}{r} \\
& u_{r r}=\frac{\partial u}{\partial r}=-2 \frac{u}{r}+\frac{\alpha(1+v)}{3(1-v)} T(r)
\end{aligned}
$$

Stresses

$$
\sigma_{i k}=\frac{E}{1+v}\left(u_{i k}+\frac{v}{1-2 v} u_{l l} \delta_{i k}\right)
$$

Here $\mathrm{E}$ is Young's modulus, E=74 GPa for fused silica.

Hoop tensile stresses are the most dangerous:

$$
\sigma_{\theta \theta}=\frac{\alpha E}{3(1-v)(1-2 v)}((1-2 v) \tilde{T}(r)+v T(r)) ; \tilde{T}=\frac{\int_{0}^{r} T(r) r^{2} d r}{r^{3}}
$$

Maximal hoop stress occurs at $\mathrm{a} \sim \mathrm{r}$ and is given by

$$
\sigma \sim \alpha E T
$$

Hoop stress is independent of beam size and for $\mathrm{T} \sim 2000^{\circ} \mathrm{C}, \sigma \sim 0.1 \mathrm{GPa}$ which is comparable with the silica tensile strength $0.05 \mathrm{GPa}$. Of course, we cannot conclude that the silica will inevitably crack as a result of processing. These estimates are uncertain by a factor of a few. Also, the maximum stress occurs where the glass is hot and ductile, cracking takes place during the cooling stage when thermal gradients are somewhat smoothed so stresses at that point will be 
smaller. But the above estimate does point out the importance of keeping the surface temperature low during the laser polishing process.

\subsubsection{Conclusions concerning $\mathrm{CO} 2$ laser processing}

Our analysis shows that two regimes of $\mathrm{CO} 2$ surface treatment of fused silica are possible. The first consists of gentle ablation with long time $(60 \mathrm{sec})$ low intensity exposure in which material flow is insignificant. Material removal is by evaporation and relatively slow. The second regime involves short time $(0.1 \mathrm{sec})$ exposure by more intense beams. In this case, lateral hydrodynamic flow competes with evaporation, the material removal rate is much larger, and conspicuous rims form around the central pit. Both of these regimes have been observed experimentally.

One can imagine two types of damage treatment by $\mathrm{CO} 2$ laser irradiation. In the prophylactic case, the laser beam scans the entire surface of an optic. A surface layer is melted and all cracks and voids are thermally healed. Unfortunately, the above analysis indicates that in this situation inhomogeneity of laser radiation, evaporation and stress will adversely affect surface flatness if the temperature is high enough to anneal cracks in reasonable time.

In the second approach, one mitigates only already damaged sites. In this case, gentle melting and evaporation is possible so the resulting surface is smooth enough to possibly improve the damage threshold. The resultant crater, if unfilled, can distort the wave front of the light passing through it. P. Wegner and M. Key are presently considering this importance of this effect. In this regard, the exact shape, including any rims will determine the degree of downstream intensification.

\section{Modeling related experiments}

Two sets of experiments were undertaken in a preliminary effort to measure energy partition and shock strength factors of importance for damage theoretical models.

The first, performed by H. Tom ${ }^{18}$ at UC Riverside, employed a novel three color pump-probe technique to produce time resolved images of structural changes accompanying high fluence bulk laser damage initiation in DKDP. The pump (damaging pulse) was $15 \mathrm{~ns} 1.06 \mu \mathrm{m}$ light. The three probes were of three different colors, time delayed, pulselength 3-7 ns and detected by a CCD to get time resolution. Fluences were high, but not unreasonable for $1.06 \mu \mathrm{m}$ small spots, i.e. up to about $70 \mathrm{~J} / \mathrm{cm} 2$. We supplied samples for these experiments. The results showed initial "melting" around the absorption site, followed by shock generation and cracking ( Fig. 12) along particular crystal directions $((2,2,3)$ direction especially). The shocks observed were weak. One of the interesting results was the partial "healing" of microcracks that appeared during the laser energy absorption. 
The second set of experiments, performed by A. Salleo ${ }^{19}$ and R. Russo at UC Berkeley, used a 35 picosecond pump-probe approach to imaging shockwaves in air and in silica accompanying the absorption of a high fluence beam at the silica surface. A picosecond pump pulse was used because of availability of the laser and the short time of this project. This was envisioned as a proof of principle experiment to show the potential usefulness of this approach for nanosecond duration laser pulses. The experiments showed clear shock profiles in air and in glass. Shockwaves generated in air at the front surface were found to be stronger than those generated at the rear-surface. Less than $35 \%$ of the energy incident on the surface drives the air shockwaves at the rear-surface. Up to $90 \%$ of the incident energy drives the air shockwaves at the front surface. Laser-plasma interaction is responsible for this difference and for limiting the amount of energy deposited inside the sample during front-surface ablation. At the front surface, laser-plasma interactions during the pulse cause energy absorption in the heated air thus limiting the efficiency of energy deposition in the solid. At the rear-surface the onset of front-surface absorption and selffocusing limited energy deposition. Energy deposition is confined inside the material when the beam interacts with the rear-surface and dissipated in the air when the beam interacts with the front-surface. Therefore, for a given total absorbed laser energy, material removal efficiency is much higher at the rear surface than at the front surface. These experiments showed that the shockwave in air follows a simple blastwave model $\{11]$ until they degenerate into acoustic waves.

The two sets of experiments demonstrated the potential usefulness of such pump-probe investigations of energy deposition and shockwave generation. Due to the limited duration of the project, it was not possible to modify the protocols to more closely investigate the regime of nanosecond UV laser pulses at surfaces and in the bulk of materials. This work should be extended in future efforts.

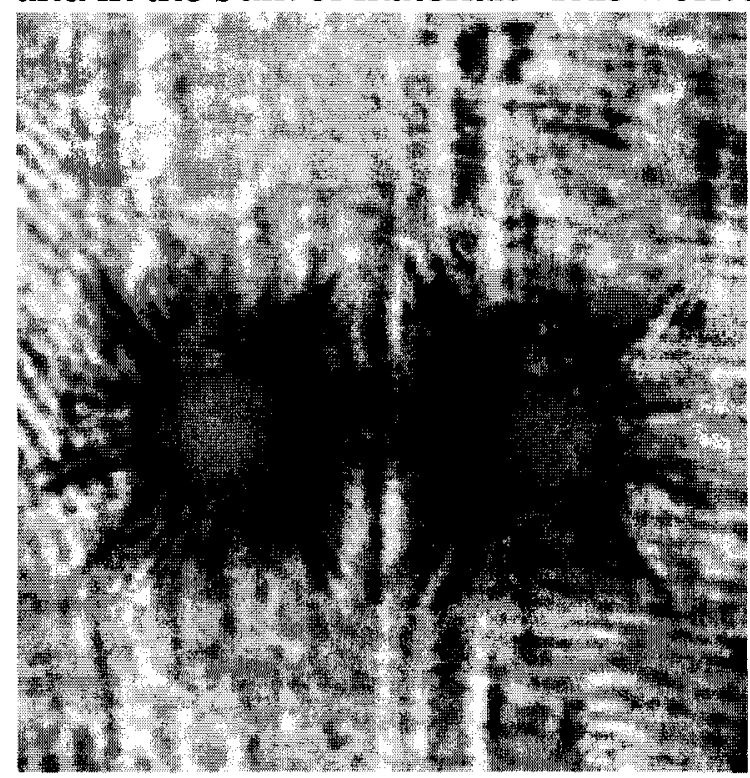

Fig. 12: Near surface DKDP damage image obtained in total internal reflection geometry (image has a

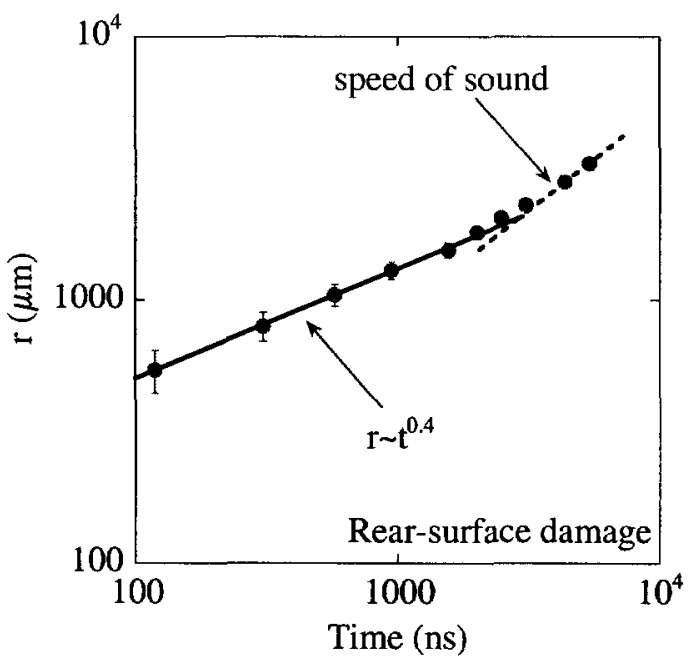

Fig. 13: Scaling with time of position of shockwave in air generated by absorption of laser energy at rear surface of fused 
vertical mirror plane). Delay time of 45 ns after the pump pulse. The image size is $195 \times 202 \mu \mathrm{m}^{2}$. silica. Initial slope indicative of blast wave which later becomes acoustic.

\section{Conclusions and recommended future work}

Our results outlined above aid basic understanding of processes (role of nanoabsorbers, crater scaling) involved in laser initiated damage to optics. Clearly further simulation and experiment are required to explore the complex physics/chemistry/mechanics involved in laser damage. We have begun detailed molecular dynamics and radiation-hydrodynamic simulations of shockwave damage and crater formation in fused silica. These simulations are beginning to unravel the structural and electronic changes that accompany damage initiation, and, therefore, form the basis for understanding damage growth over many pulses. These simulations can yield significant insight into damage processes, especially if intelligently informed by experiment. In this regard, a version of the UCB pump-probe experiment carried out with nanosecond UV laser pulses would be very helpful.

Our results not only help understand mechanisms underlying laser damage, but also the related mechanisms which can be relied on to "heal" damage to greatly reduce its subsequent growth.

\section{Appendix A : Relaxation of relief in viscous liquid.}

When glass is melted due to laser irradiation, microcracks tend to relax because of surface tension. We estimate the time for this relaxation. Consider local surface perturbation $\eta(x)$. We assume the size of a microcrack is smaller than the thickness of the melt layer so the deep liquid model can be used. The liquid can be treated as incompressible. Because of the high viscosity, the motion of the liquid cannot be described by a velocity potential.

The equations of motion are

$$
\begin{aligned}
& \frac{\partial v_{x}}{\partial t}=v\left(\frac{\partial^{2} v_{x}}{\partial x^{2}}+\frac{\partial^{2} v_{x}}{\partial z^{2}}\right)-\frac{\partial p}{\rho \partial x} \\
& \frac{\partial v_{z}}{\partial t}=v\left(\frac{\partial^{2} v_{z}}{\partial x^{2}}+\frac{\partial^{2} v_{z}}{\partial z^{2}}\right)-\frac{\partial p}{\rho \partial z} \\
& \frac{\partial v_{x}}{\partial x}+\frac{\partial v_{z}}{\partial z}=0
\end{aligned}
$$


We are looking for a harmonic solution proportional to $e^{-i \omega t+i k x}$ which damps out at large negative $z$. Due to the second order derivatives with respect to $z$, the solution must contain two damping exponents. It is possible to check that the following ansatz satisfies Eqs.(A.1)

$$
\begin{aligned}
& v_{x}=e^{-i \omega t+i k x}\left(A e^{k z}+B e^{m z}\right) \\
& v_{x}=-i e^{-i \omega t+i k x}\left(A e^{k z}+\frac{k}{m} B e^{m z}\right) \\
& \frac{p}{\rho}=e^{-i \omega t+i k x} \frac{\omega}{k} A e^{k z} ; m^{2}=k^{2}-\frac{i \omega}{v}
\end{aligned}
$$

The constants $\mathrm{A}$ and $\mathrm{B}$ must be determined from the boundary conditions.

$$
\sigma_{i k} n_{k}=\alpha \frac{\partial^{2} \eta}{\partial x^{2}}
$$

Here $\sigma$ is the viscous stress tensor, $\mathbf{n}$ - the unit vector normal to the surface, $\alpha$ the surface tension coefficient. In components, we have

$$
\begin{aligned}
& \sigma_{z z}=-p+2 \rho v \frac{\partial v_{z}}{\partial z}=\alpha \frac{\partial^{2} \eta}{\partial x^{2}} \\
& \sigma_{z x}=\frac{\partial v_{z}}{\partial x}+\frac{\partial v_{x}}{\partial z}=0
\end{aligned}
$$

The boundary conditions apply at $z=0$. From them, one can determine constants $\mathrm{A}, \mathrm{B}$ and frequency $\omega$.

Substituting (9.2) into the second of the equations (A.4) we have

$$
2 A+\frac{k^{2}+m^{2}}{k m} B=0
$$

Differentiating the first of the relations (A.4) by time and substituting $\mathrm{v}_{\mathrm{z}}$ for $\frac{\partial \eta}{\partial t}$ we have

$$
i \frac{\omega^{2}}{k} A-2 \omega k(A+B)=i \frac{\alpha k^{2}}{\rho}\left(A+\frac{k}{m} B\right)
$$


First, consider the situation when surface tension is absent. From (A.5), (A6) we have the dispersion relation

$$
\left(2-\frac{i \omega}{v k^{2}}\right)^{2}=4 \sqrt{1-\frac{i \omega}{v k^{2}}}
$$

This dispersion equation coincides with equations describing the damping of gravity waves in viscous liquid for gravity equal zero.

Consider the role of surface tension. Our equations have a small parameter $\omega / \mathrm{vk}^{2}$. We will see later that in our case it is very small, for a crack of scale $1 \mu \mathrm{m}$ it is about $10^{-11}$. Expanding in this parameter, the equation (A.5) can be written as

$$
A+B \approx 0.25\left(\frac{\omega}{v k^{2}}\right)^{2} B
$$

With accuracy of second order in our small parameter, $A+B=0$. Using this in Eq.(A.6), we get the final answer

$$
\omega=-i \frac{\alpha k}{2 \rho v}
$$

We see that the characteristic decay time for surface perturbation is

$$
\tau=\frac{2 \rho \nu}{\alpha k}
$$

\section{Appendix B: Publications and presentations}

"Physical understanding of $3 w$ damage via modeling", M.D. Feit, $3 \omega$ damage workshop, LLNL, March 30-31, 2000 UCRL-VG-138229

. "Time-resolved imaging study of material modification and crack formation during laser damage": Harry W. K. Tom, M.D. Feit, Technical Progress Report: UCRP LS00-006 (April 27, 2000)

"Rear surface laser damage on $355 \mathrm{~nm}$ silica optics due to Fresnel diffraction at front surface contamination particles", F.Y. Génin, M.D. Feit, M.R. Kozlowski, A.M. Rubenchik, A. Salleo, UCRL-JC-133839 Appl. Optics 39, 3654-63 (20 July 2000) 
"Scaling relations for laser damage initiation craters", A.M. Rubenchik, M.D. Feit, XXXII Annual symposium on optical materials for high power lasers, Boulder Oct. 1618, 2000, UCRL-JC-139647 (to appear in proceedings)

"Analysis of bulk DKDP damage distribution, obscuration and pulse length dependence", M.D. Feit, A.M. Rubenchik, and M. Runkel, XXXII Annual symposium on optical materials for high power lasers, Boulder Oct. 16-18, 2000, UCRL-JC-139649 (to appear in proceedings)

"Results of pulse-scaling experiments on rapid-growth DKDP triplers using the optical sciences laser at $351 \mathrm{~nm}$ ", M. Runkel, A. Burnham, D. Sell, M.D. Feit, A.M. Rubenchik, R. Fluck, P. Wegner, XXXII Annual symposium on optical materials for high power lasers, Boulder Oct. 16-18, 2000, UCRL-JC-139623 (to appear in proceedings)

"Growth of Laser Initiated Damage in Fused Silica at 351nm", M.A. Norton, Z. Wu, L.W. Hrubesh, A.M. Rubenchik, M.D. Feit, D. Milam, W.A. Molander, P. Wegner, and M.R. Koslowski, XXXII Annual symposium on optical materials for high power lasers, Boulder Oct. 16-18, 2000 UCRL-JC-139624 (to appear in proceedings)

"Atomistic simulations of crack propagation in $\mathrm{SiO}_{2}$ under extreme conditions of pressure and temperature", M. -J. Caturla, A. Kubota, T. Lenosky, V. Bulatov, T. Diaz de la Rubia, M.D. Feit, Materials Research Society, Boston, (Nov 2000) UCRL-VG-140925

"Physical understanding of 3w damage through modeling" (invited), M.D. Feit, LaserMaterials Interaction Workshop, Livermore, (Sept. 14-15, 2000), UCRL-VG-138229

"Modeling of laser induced damage in NIF UV optics", LS\&T Technical Program Update (October 2000), UCRL-TB-136126-00-09

Record of invention IL-10788: Method for producing damage resistant optics, L. Hackel, A. Burnham, M.R. Kozlowski, P. Wegner, M.D. Feit (2000)

"Energy deposition at front and rear surface during picosecond laser interaction with fused silica", A. Salleo, F. Y. Génin, M. D. Feit, A. M. Rubenchik, T. Sands, R. E. Russo, (accepted for publication in J. Appl. Phys.)

\section{References}

1 "Analysis of bulk DKDP damage distribution, obscuration and pulse length dependence", M.D. Feit, A.M. Rubenchik, and M. Runkel, XXXII Annual symposium on optical materials for high power lasers, Boulder Oct. 16-18, 2000, UCRL-JC-139649 2 "Results of pulse-scaling experiments on rapid-growth DKDP triplers using the optical sciences laser at 351 nm", M. Runkel, A. Burnham, D. Sell, M.D. Feit, A.M. Rubenchik, R. Fluck, P. Wegner, XXXII Annual symposium on optical materials for high power lasers, Boulder Oct. 16-18, 2000, UCRL-JC-139623 
3 "Nd-doped phosphate glasses for high-energy/high-peak-power lasers", J. H. Campbell, T.I. Suratwala, J. Non-Crys. Sol., 263-264, 318-41 (2000)

4 "Modeling of laser-induced surface cracks in silica at $355 \mathrm{~nm}$ ", M.D. Feit, J.H. Campbell, D.R. Faux, F.Y. Genin, M.R. Kozlowski, A.M. Rubenchik, R.A. Riddle, A. Salleo, J.M. Yoshiyama, Proceedings XXIX Annual Symposium Laser-induced Damage in Optical Materials, Boulder, Co, Oct 6-8, 1997 SPIE 3244, 350-355 (1998)

5 "Scaling relations for laser damage initiation craters", A.M. Rubenchik, M.D. Feit , XXXII Annual symposium on optical materials for high power lasers, Boulder Oct. 1618, 2000, NIF-0055822, UCRL-JC-139647

- "Impact ejection, spallation and the origin of meteorites", H. Melosh, Icarus 59, 234$260,(1984)$

7 "An analysis of cratering data from desert alluvium", M.D. Nordyke, J. Geophys. Res. 67,1967-1974, (1962)

8 "Carbon dioxide laser polishing of fused silica surfaces for increased laser-damage resistance at 1064 nm", P.A. Temple, W.H. Lowdermilk, D. Milam, Appl. Opt. 21, 324955 (1982)

9 Handbook of Optical Constants in Solids, E. D. Palik, ed., Academic Press (1985)

${ }^{10}$ Instabilities in Laser-matter interaction, S. Anisimov, V.A. Khokhlov, CRC Press (1995)

${ }^{11}$ Physics of shock waves and high-temperature hydrodynamic phenomena, Ya. B. Zeldovich, Yu. P. Raizer, Academic Press (1967)

${ }^{12}$ L. Hrubesh, unpublished (2000)

${ }^{13}$ Glass, H.Schoize, Springer- Verlag, (1991)

${ }_{14}$ Properties, processing and applications of glass and rare earth-doped glasses for optical fibres, D.Hewak, Ed, London, UK: INSPEC, (1998)

15 "Test protocol and details for samples SC40067, SC40031 and SC40029", R. Brusasco, LLNL memo RMB 00-007 (Aug. 19, 2000)

16 B. Penetrante, unpublished (2000)

${ }^{17}$ The Handbook of Glass Manufacture, 3rd ed.v.2, p.930, Ashlee Publishing Co. (1984)

18 "Time-resolved imaging study of material modification and crack formation during laser damage" : Harry W. K. Tom, M.D. Feit, Technical Progress Report: UCRP LSO0006 (April 27, 2000); "Ultrafast Time-Resolved Multi-Probe Imaging of Laser Damage in Transparent Solids H. Jiang, J. McNary, H.W.K. Tom, M. Yan, H.B. Radousky and S.G. Demos, UCRL-JC-139577 (July 2000)

19 "Energy deposition at front and rear surface during picosecond laser interaction with fused silica", A. Salleo, F. Y. Génin, M. D. Feit, A. M. Rubenchik, T. Sands, R. E. Russo, (accepted for publication in Appl. Phys. Lett.)

This work was performed under the auspices of the U.S. Department of Energy by the University of California, Lawrence Livermore National Laboratory under Contract No. W-7405-Eng-48. 